\title{
The PNPase, exosome and RNA helicases as the building components of evolutionarily-conserved RNA degradation machines
}

\author{
Sue Lin-Chao ${ }^{1, *}$, Ni-Ting Chiou ${ }^{1} \&$ Gadi Schuster ${ }^{2}$ \\ ${ }^{1}$ Institute of Molecular Biology, Academia Sinica, Taipei, 11529, Taiwan; ${ }^{2}$ Department of Biology, \\ Technion - Israel Institute of Technology, Haifa, 32000, Israel \\ Received 22 January 2007; accepted 27 February 2007 \\ (c) 2007 National Science Council, Taipei
}

Key words: RNase PH, PNPase, Exosome, RNA helicase, RNA degradation, RNA polyadenylation

\begin{abstract}
The structure and function of polynucleotide phosphorylase (PNPase) and the exosome, as well as their associated RNA-helicases proteins, are described in the light of recent studies. The picture raised is of an evolutionarily conserved RNA-degradation machine which exonucleolytically degrades RNA from $3^{\prime}$ to $5^{\prime}$. In prokaryotes and in eukaryotic organelles, a trimeric complex of PNPase forms a circular doughnutshaped structure, in which the phosphorolysis catalytic sites are buried inside the barrel-shaped complex, while the RNA binding domains create a pore where RNA enters, reminiscent of the protein degrading complex, the proteasome. In some archaea and in the eukaryotes, several different proteins form a similar circle-shaped complex, the exosome, that is responsible for $3^{\prime}$ to $5^{\prime}$ exonucleolytic degradation of RNA as part of the processing, quality control, and general RNA degradation process. Both PNPase in prokaryotes and the exosome in eukaryotes are found in association with protein complexes that notably include RNA helicase.
\end{abstract}

\section{Polynucleotide phosphorylase (PNPase), a major exoribonuclease in bacteria and organelles}

PNPase (EC 2.7.7.8) was discovered by GrunbergManago and Ochoa while they were studying the mechanism of biological phosphorylation in Azotobacter vinelandii [1] and was characterized by Littauer and Kornberg in studies of the nature of ribonucleotide incorporation into nucleic acids in Escherichia coli [2]. PNPase was the first enzyme to be identified that can catalyze the formation of polynucleotides from ribonucleotides. However, unlike the RNA polymerases, PNPase does not require a template and cannot copy one. When a mixture of ribonucleotide diphosphates (NDPs) serves as substrates for the polymerization reaction the ensuing polymerization reaction forms a random copolymer.

*To whom correspondence should be addressed. Fax: + 886-22782-6085; E-mail: mbsue@gate.sinica.edu.tw
PNPase catalyzes both processive $3^{\prime}$ to $5^{\prime}$ phosphorolysis and $5^{\prime}$ to $3^{\prime}$ polymerization of RNA [2-4]. In E. coli, PNPase is mostly active in $3^{\prime}$ to $5^{\prime}$ phosphorolysis during RNA degradation and $3^{\prime}$ end processing, but recently a substantial degree of activity in the polymerization of heteropolymeric tails has also been reported [5, 6]. Moreover, in spinach chloroplasts, cyanobacteria and Grampositive bacteria, PNPase is suggested to be the major polyadenylating enzyme [7, 8]. PNPase was also reported to be a global regulator of virulence and persistence in Salmonella enterica [9]. Part of the PNPase population in E. coli is associated with the endoribonuclease RNase E, an RNA helicase, enolase, and possibly other proteins in a highmolecular weight complex called the degradosome [10-14]. Human PNPase was identified in an overlapping pathway screen to discover genes displaying coordinated expression as a consequence of terminal differentiation and senescence of melanoma cells [15-17]. In human cells PNPase 
is mostly located in the mitochondrial intermembrane space and may not play the major role in the processing and degradation of RNA that it plays in bacteria, chloroplasts and plant mitochondria $[18,19]$.

RNase PH (EC 2.7.7.56) is the other member in bacteria of the Pi-dependent $3^{\prime}$ to $5^{\prime}$ exoribonucleases. The best characterized function of this enzyme is trimming of tRNA precursors at their $3^{\prime}$ ends [20, 21]. RNase PH homologs are small single domain proteins that are distributed among all three primary kingdoms. In archaea and eukaryotes they form the core of the exosome complexes (Figure 2); in bacteria, six RNase $\mathrm{PH}$ polypeptides form a homohexameric structure $[22,23]$ that is similar to that of the PNPase and the exosome (see below; Figures 2 and 3).

\section{Similar structure of the RNase PH, PNPase and exosome complexes}

The amino acid sequences of PNPases from bacteria, as well as from the nuclear genomes of plants and mammals, display a high level of homology and feature similar structures comprised of five motifs (Figures 1 and 2) [12, 24-28]. The protein is composed of two domains that are related to the RNase PH enzyme. These domains are termed the phosphorolysis domains or RNase $\mathrm{PH}-$-like $(\mathrm{PH})$ domains. The other two domains are homologous to the $\mathrm{K} 1$ and $\mathrm{S} 1$ domains characterized in RNA binding proteins. The PNPases of plants and animals are directed to the chloroplast and mitochondria by an additional $\mathrm{N}$-terminus extension encoding a transit peptide. The transit peptide is then removed from the protein after translocation. The three-dimensional structure of the PNPase from the bacterium Streptomyces antibioticus has been revealed by X-ray crystallographic analysis. The enzyme is a ring (doughnut)shape formed by a homotrimeric complex, with the hexameric PH-domains surrounding a central channel that can accommodate a single-stranded RNA molecule (Figure 3) [12, 27].

Mutation analysis of the E. coli PNPase suggests that the phosphorolytic active site is located at the 2nd core domain [32]. However, whether or not the 1st core domain is also active is still an open question. In the bacteria Streptomyces antibioticus the 2nd core domain harbors the phosphorolytic site while the 1 st core domain is engaged in the synthesis of the "magic spot" nucleotide ppGppp [27]. The domains of the spinach chloroplast PNPase have been analyzed in detail [24]. It was found that the 1st core domain, which was predicted to be inactive in bacterial enzymes, was active in RNA degradation but not in polymerization. The 2 nd core domain was found to be only active in the degradation of polyadenylated RNA. The high affinity poly(A) binding site was localized to the S1 domain.

No PNPase is found in members of the Archaea domain. However, several hyperthermophilic and methanogenic Archaea contain a protein complex that is composed of two proteins (Rrp41 and Rrp42) homologous to RNase $\mathrm{PH}$ and one protein containing a $\mathrm{KH} / \mathrm{S} 1$ domain [33]. Three copies of the three proteins form a nine-subunit complex termed the archaeal exosome that, as with PNPase, is responsible for the polyadenylation and degradation of RNA [29, 30, 34-37]. Moreover, crystallographic analysis of archaeal exosome has revealed a structure very similar to the PNPase of bacteria (Figure 3). The eukaryotic exosome, which performs $3^{\prime}$ to $5^{\prime}$ RNA degradation in the cytoplasm and nucleus [37-43], is composed of $10-11$ proteins and is considerably more complicated than that of the Archaea (Table 1). Nonetheless, alignment of the proteins of this complex clearly points to a great similarity between the number and characteristics of the different domains in the archaeal and eukaryotic exosomes and the PNPases (Figure 2; Table 1). The same core structure is formed: a ring-shaped structure created by six different $\mathrm{PH}$ like polypeptides, where three different subunits each contribute a $\mathrm{KH}$ and an $\mathrm{S} 1$ domain (Figure 3) [31]. In addition to RNase PH-like polypeptides, the yeast exosome core contains a novel subunit with hydrolytic $3^{\prime}$ exonuclease activity (Rrp44 or Dis3) that belongs to the family of RNase $\mathrm{R}$ and RNase II in bacteria (Table 1) [38, 49].

These observations imply that the bacterial and organelle PNPases and the archaeal and eukaryotic exosomes constitute a unique ring-shaped machine, which has evolved naturally to phosphorolytically or/and hydrolytically degrade and polymerize RNA (Table 1). This ancestral machine was already present before the separation of the bacteria, archaea and eukaryotes (Figure 1). It 


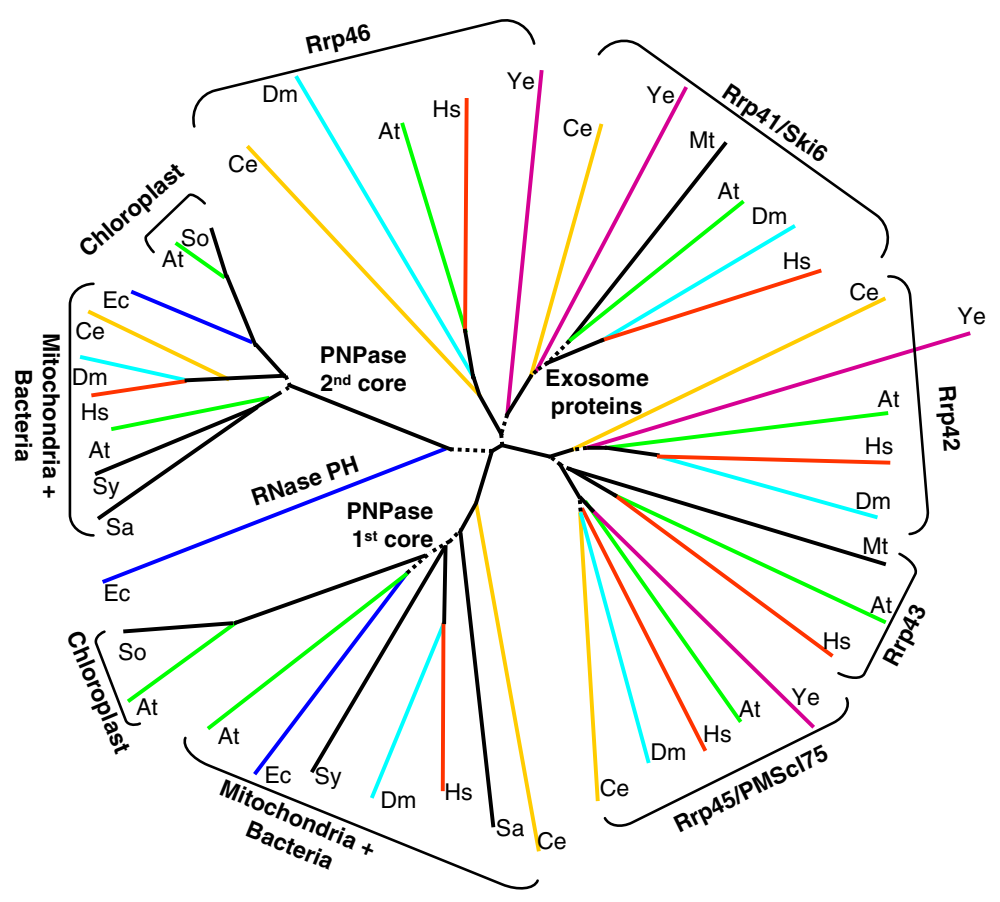

Figure 1. Phylogenetic tree of the RNase PH domains of bacterial and organelle PNPases and exosome proteins. The 1st and 2nd core domains of PNPases, the related exosome proteins and the E. coli RNase $\mathrm{PH}$ were aligned using the Clustal X multiple sequence alignment tool, and a phylogenetic tree was constructed as described in Ref. [24]. Proteins from the same organism have the same color. The dotted lines indicate regions of the tree where the bootstrap value was less than $50 \%$; the validity of these regions is therefore low. The organisms are: At, Arabidopsis thaliana; So, Spinacia oleracea; Hs, Homo sapiens; Ec, Escherichia coli; Sa, Streptomyces antibioticus; Sy, Synechocystis sp. PCC6803; St, Staphylococcus aureus; Dm, Drosophila melanogaster; Ce, Caenorhabditis elegans; Ye, Saccharomyces cerevisiae; and Mt, Methanobacterium thermoautotrophicum. [Reproduced with permission of the American Association of Plant Biology from ref. 28 (Yehudai-resheff et al. 2003)].

is an interesting to postulate why this machinery separated into several different proteins in Archaea and eukaryotes while remaining as one protein in bacteria and organelles. Alternatively, it could be hypothesized that the RNase $\mathrm{PH}, \mathrm{S} 1$ and $\mathrm{KH}$ domains were functionally assembled into these

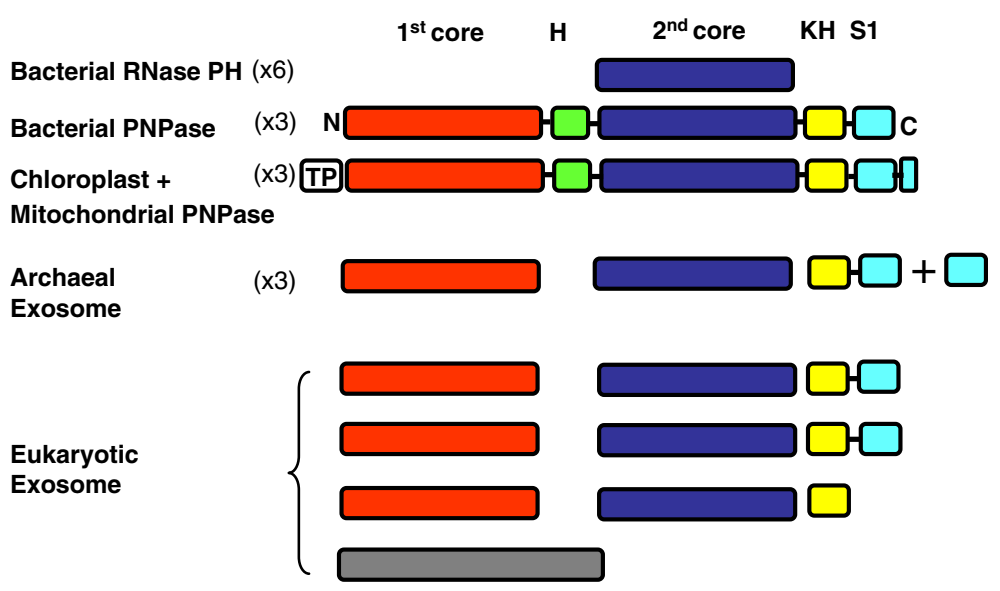

Figure 2. Domain analysis of the RNase PH, the bacterial and organelle PNPase in comparison with the archaeal and eukaryotic exosomes. The two core RNase PH domains of PNPase are shown in red and dark blue and the KH and S1 domains are shown in yellow and pale blue, respectively. The exosome protein related to the bacterial RNase II is shown in gray. Note that the PNPase enzyme is a homotrimer, as indicated by the $(\times 3)$ label, which makes a complex with the same number of RNase PH core domains. 

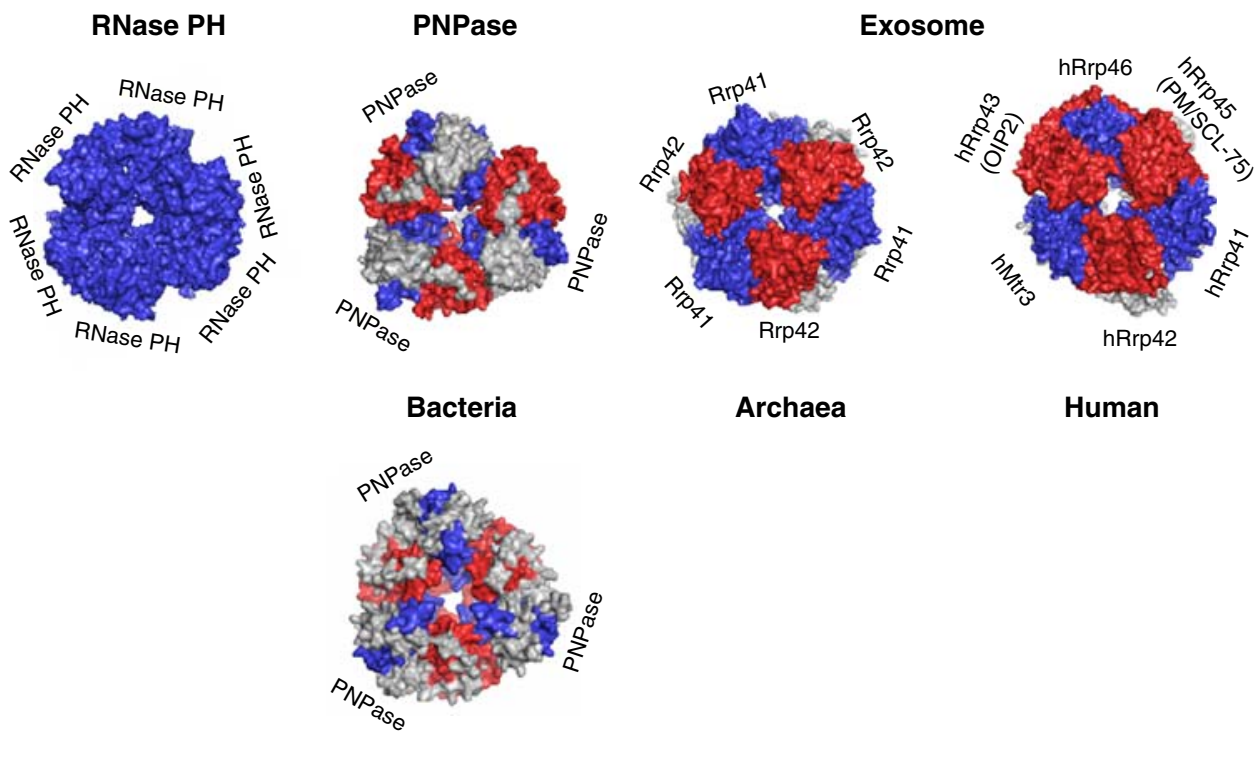

Archaea

Human

\section{Chloroplast}

Figure 3. Similarities in the structure of the RNase PH and $3^{\prime} \rightarrow 5^{\prime}$ RNA degradation machines: the PNPase and the exosome. The structure of the RNase PH [22, 23], the bacterial PNPase [27], archaeal [29, 30] and eukaryotic [31] exosomes, as well as the predicted structure of the chloroplast PNPase [24], are shown in order to compare the ring shape of these complexes. The molecular surfaces of these structures are represented in the same view and colored as in Figure 2. The structures were generated using Pymol (see The PyMOL Molecular Graphics System in Further Information).

circle-type RNA phosphorolysis machines as the result of non-related evolutionary processes.

\section{Association of PNPase and the exosomes with other proteins}

In E. coli, part of the PNPase population is associated with the endonuclease RNase E, RNAhelicase and the glycolytic enzyme enolase to form a complex termed the degradosome [51], in which the scaffold is the RNase E [59]. However, another part of the PNPase population in the E. coli cell is associated with the RNA helicase alone (see discussed below) [50]. Unlike the PNPase/exosome complex that exists in almost all organisms as a general machine for RNA phosphorolysis, the degradosome appears to be unique to $E$. coli and perhaps some other related bacteria, and disrupting its assembly does not result in lethality. The PNPase or PNPase protein complex in the degradosome executes its processive $3^{\prime}$ to $5^{\prime}$ phosphorolysis or degradation of RNA species upon endonucleolytic cleavage by RNase E. In the E. coli degradosome machine, PNPase acts as an integral component, like RNA-helicase and enolase. The architecture of the PNPase complex in RNA degradosome in terms of binding to the tetrameric complex of RNase E still awaits structural studies [60, 61].

In crude cell extracts of $E$. coli, PNPase is heterogenous [62] and exists in two active forms, A and $\mathrm{B}$, with molecular masses of $\sim 252$ and $365 \mathrm{KDa}$, respectively [63]. The A form contains three identical catalytic $(\alpha)$ subunits and is present as a homotrimeric exoribonuclease (i.e. $\alpha_{3}$ structure), whose structure parallels that of the hexameric RNase $\mathrm{PH}$ complex and the core of the eukaryotic exosome, as described above. The B form consists of two types of chain $\alpha$ and $\beta$, and has been assigned a structure of $\alpha_{3} \beta_{2}$ [63]. The molecular mass of the $\beta$ chain ranges between from $48 \mathrm{KDa}$ to $50 \mathrm{KDa}[63]$ and co-immunoprecipitation, in vitro reconstitution and protein interaction analyses show that the PNPase $\beta$-subunit is the RhlB, a DEAD-box RNA helicase; the PNPase $\alpha$-subunit associates with RhlB ( $\beta$ subunit) by a direct interaction, which is not dependent on the formation of the degradosome [50]. RhlB helicase promotes double-stranded RNA 


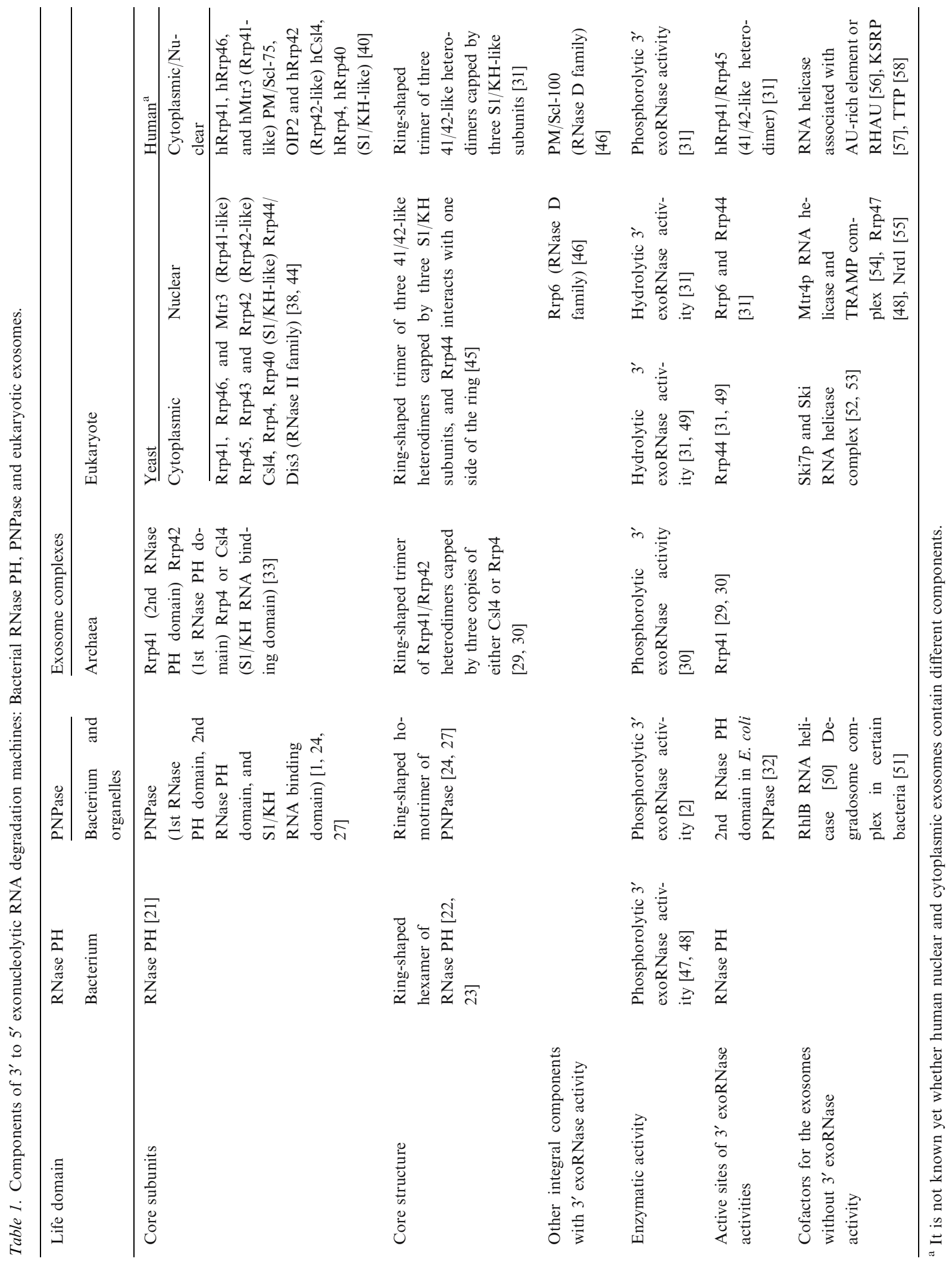


degradation by the PNPase [50]. Unlike the RNase E-RhlB interaction, the interaction between PNPase $\alpha$ - and $\beta$-subunits is rather unstable, which most likely ensures a transient association between the protein and the ring-shaped machine core, as with accessory proteins of the eukaryotic exosome [40].

The RNA degradation function of yeast nuclear exosome is promoted by a nuclear polyadenylation complex termed the TRAMP complex [54]. The TRAMP complex consists of a poly(A) polymerase (Trf4p and/or Trf5p), a zinc knuckle protein (Air2p) and a RNA-helicase (Mtr4p). The Mtr4p RNA helicase is a DEVH-box RNA helicase and is commonly known as an activating cofactor of the exosome [64]. The Mtr4p RNA helicase, which is shared between the TRAMP and the exosome complexes, is likely to be important in vivo in accelerating TRAMP-dependent exosome action on nuclear RNA species containing secondary structures at their $3^{\prime}$ termini. The molecular mechanism by which TRAMP-exosome distinguishes a structured RNA species from others is unknown.

Yeast cytoplasmic exosome, through the $\mathrm{G}$ protein Ski7p, interacts with a Ski ternary-complex consisting of the RNA helicases Ski2p, Ski3p and Ski8p [52, 53]. The Ski ternary-complex is a cofactor promoting exosome $3^{\prime}$ to $5^{\prime}$ mRNA degradation. Ski7p interacts with the exosome independently of its interaction with Ski ternary-complex through a distinctive segment in the N-terminal of Ski7p. However, Ski7p interaction with both exosome and Ski ternary-complexes is required for the $3^{\prime}$ to $5^{\prime}$ mRNA decay. As the Ski7p is dynamically shared between Ski ternary-complex and exosome, this might suggest it plays a role in the activation of RNA helicase ternary-complex, and the recruitment and activation of cytoplasmic exosome. The Ski ternary-complex and Ski7p are the cofactors that determine specific substrates of the cytoplasmic exosome. Interestingly, the yeast exosome, even though preserving the ring-shaped structure of the PNPase/exosome complexes, does not display any phosphorolytic activity. Unlike the phosphorolytic human exosome (see below), in yeast only hydrolytic RNA degradation activity has been detected [31, 65] (Table 1).

Human cytoplasmic exosome, through its interaction with various cellular proteins specifically bound to AU-rich elements (AREs) in the 3' untranslated region of unstable mRNAs, recruits ARE-containing mRNA species and has been proposed to be responsible for the rapid degradation of ARE-containing mRNA species in human cells by $3^{\prime}$ to $5^{\prime}$ RNA degradation [56-58]. ARE binding proteins such as the RHAU, a putative DExH RNA helicase, can facilitate both mRNA deadenylation and decay through direct interactions with both the deadenylase PARN and the exosome [56]. RHAU can also interact with other AU-rich binding proteins (e.g. NFAR1 and HuR) through an RNA-dependent mode. Like the TRAMP and Ski complexes of yeast exosomes, the RHAU or RHAU-PARN complexes are the cofactors that select specific ARE-containing mRNA species for the exosome.

These studies suggest that cofactors most likely play an essential role in determining the substratespecificity of different types of exosomes. Interestingly, RNA helicase is a common cofactor for all of the exosome species that participate in exosome-mediated RNA degradation. One of the possible functional roles of RNA helicase in accelerating exosome action is that of a "molecular motor" coupled to specific RNA binding proteins to drive the mechanics of complex RNA remodeling/decay reactions [56]. The specificity of any protein interaction between RNA helicase and RNA exosome thus might be important in facilitating the admittance of certain RNA species to the RNA exosome. Confirmation will come from future biochemical, genetic and/or structural studies of RNA helicase and the exosome.

\section{The biological function of PNPase and exosome}

PNPase and the exosome are heavily engaged in the $3^{\prime}$ to $5^{\prime}$ exonucleolytic degradation of RNA. The important role of the eukaryotic exosome in the quality control mechanisms of RNA degradation and gene expression is also well established [41]. As mentioned above, PNPase and the archaeal exosome are also responsible, either alone or together with poly(A)-polymerase, for polymerization during the degradation process. When PNPase or the archaeal exosome is the polymerizing enzyme, heteropolymeric tails composed mostly of adenosine but also of other nucleotides are produced $[5,8,36,66]$. Heteropolymeric tails were also recently identified in human cells [67]. 
Whether or not these tails are produced by the eukaryotic exosome, which functions both as a degrader and polymerizer like PNPase and the archaeal exosome, is still an open question. Additionally, while the yeast exosome was recently described to display only hydrolytic RNA degradation activity, the human exosome is active in phosphorolysis of RNA [31, 65].

In spinach chloroplasts, PNPase is not associated in a complex with other proteins and no posttranslational modifications, such as phosphorylation, have been identified [68]. As this complex is found in the same compartment at the same time as both RNA degradation and polymerization activities, the question of what determines the activity that it displays has been raised. As a phosphorylase, the enzyme's activity is mostly reversible and the direction towards degradation or polymerization is determined by the relative concentrations of $\mathrm{Pi}$ and nucleotide diphosphates $[24,66]$. This observation raises the prospect that PNPase can function as a modulator of the ratio of concentrations of nucleotide $/ \mathrm{Pi}$, in addition to having functions in RNA degradation and polymerization (Figure 4).

\section{Conclusions}

The exosome core contains six domains homologous to the phosphorolytic enzyme RNase $\mathrm{PH}$ and forms a ring-shaped structure similar to that formed by the homohexameric bacterial RNase $\mathrm{PH}$ and the homotrimeric PNPase enzyme, an important $3^{\prime}$ exonuclease catalyzing mRNA degradation in bacteria and organelles. The PNPase contains a duplication of RNase $\mathrm{PH}$ domain (1st and 2nd RNase PH domains) plus the two RNAbinding domains, $\mathrm{KH}$ and S1. From analysis of several bacteria, it is thought that only the 2nd RNase $\mathrm{PH}$ domain possesses phosphorolytic activity. In the archaeal exosome, as in the PNPase, only one of the two RNase PH proteins (Rrp41p, resembling the 2nd RNase $\mathrm{PH}$ in bacteria) has phosphorolytic $3^{\prime}$ exonuclease and polymerase activity. In human exosomes, only one of the six RNase PH-like proteins is phosphorolytic. Yeast exosomes (of both cytoplasmic and nuclear types) share the same ring shape; however, their phosphorolytic subunits are catalytically inactive. In all of these different machines, the PH-domain duplication in a ring-shaped structure has been evolutionarily conserved in different species and across domains, suggesting some essential geometry in the cellular machinery in bacteria, archaea, yeast and human. The correct geometric structure of the machine might be important for gating $3^{\prime}$-single stranded RNA species for RNA processing or degradation. Of the many exosome cofactors, the RNA helicases might be important for substrate recognition and recruitment, and activation of catalytic activities of various types of exosomes.
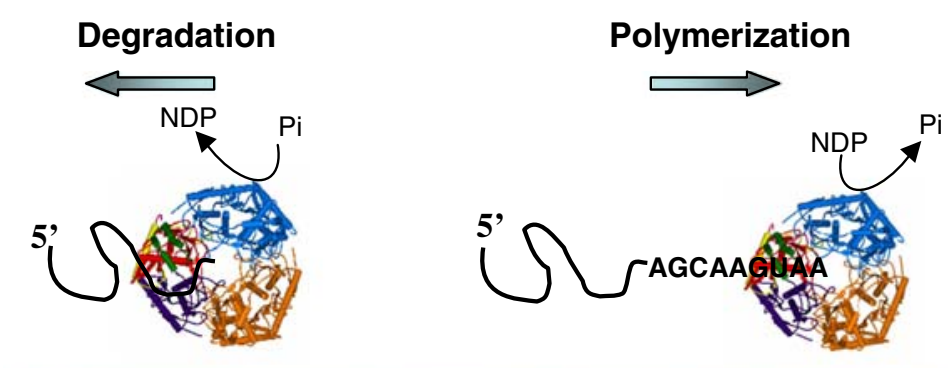

\section{$\left[\mathbf{P}_{\mathrm{i}}\right]$}

Figure 4. A model for possible modulation of enzymatic activities of PNPase and archaeal exosome as an exoribonuclease or a polymerase. The spinach chloroplast PNPase is modeled as a homotrimer according to the crystal structure of this enzyme from the bacteria Streptomyces antibioticus [27]. Since its activity could be modulated by the internal concentrations of nucleotides and $\mathrm{Pi}$, and these fluctuate as the result of PNPase (or the archaeal exosome) activity, it is possible that the enzyme is actually moving back and forth degrading and polymerizing RNA. When degrading RNA, it consumes Pi and produces nucleotides, therefore increasing the local concentration of nucleotides (left side of figure). However, when polymerizing RNA, it consumes nucleotides and produces Pi (right side of figure). Therefore, while working in one direction, and if no other mechanism controls the activity, it could reach a situation whereby changes in the local concentrations of nucleotides and Pi will cause the enzyme to turn around and work in the opposite modality. 


\section{Acknowledgments}

The authors would like to thank Drs H Wilson and SN Cohen for their critical reading and comments on the manuscript. Work in S L-C lab was supported by grants from the National Science Council, ROC (95-2311-B-001-055 \& -034), an Academia Sinica Institutional Research grant, and a JCEF research fund. Work in GS lab was supported by grants from Israel Science Foundation (ISF), United States-Israel Binational Science Foundation (BSF) and the United StatesIsrael Binational Agricultural Research and Development Fund (BARD).

\section{References}

1. Grunberg-Manago M., Oritz P.J. and Ochoa S., Enzymatic synthesis of nucleic acid like polynucleotides. Science 122 : 907-910, 1955.

2. Littauer U.Z. and Soreq H., Polynucleotide Phosphorylase. Academic Press, New York, 1982.

3. Littauer U.Z. and Grunberg-Manago M., Polynucleotide phosphorylase, In: Creighton T.E. (Ed), The Encyclopedia of Molecular Biology. John Willy and Sons Inc, New York, 1999, pp. 1911-1918.

4. Grunberg-Manago M., Messenger RNA stability and its role in control of gene expression in bacteria and phages. Annu. Rev. Genet. 33: 193-227, 1999.

5. Mohanty B.K. and Kushner S.R., Polynucleotide phosphorylase functions both as a $3^{\prime}$ to $5^{\prime}$ exonuclease and a poly(A) polymerase in Escherichia coli. Proc. Natl. Acad. Sci. USA 97: 11966-11971, 2000.

6. Mohanty B.K., Maples V.F. and Kushner S.R., The Smlike protein $\mathrm{Hfq}$ regulates polyadenylation dependent mRNA decay in Escherichia coli. Mol. Microbiol. 54: 905-920, 2004.

7. Bollenbach T.J., Schuster G. and Stern D.B., Cooperation of endo- and exoribonucleases in chloroplast mRNA turnover. Prog. Nucleic Acid Res. Mol. Biol. 78: 305-337, 2004.

8. Slomovic S., Portnoy V., Liveanu V. and Schuster G., RNA polyadenylation in prokaryotes and organelles; different tails tell different tales. Crit. Rev. Plant Sci. 25: 65-77, 2006.

9. Clements M.O., Eriksson S., Thompson A., Lucchini S., Hinton J.C., Normark S. and Rhen M., Polynucleotide phosphorylase is a global regulator of virulence and persistency in Salmonella enterica. Proc. Natl. Acad. Sci. USA 99: 8784-8789, 2002.

10. Carpousis A.J., Vanzo N.F. and Raynal L.C., mRNA degradation, a tale of poly(A) and multiprotein machines. Trends Genet. 15: 24-28, 1999.

11. Liou G.G., Jane W.N., Cohen S.N., Lin N.S. and LinChao S., RNA degradosomes exist in vivo in Escherichia coli as multicomponent complexes associated with the cytoplasmic membrane via the $\mathrm{N}$-terminal region of ribonuclease E. Proc. Natl. Acad. Sci. USA 98: 63-68, 2001.
12. Symmons M.F., Williams M.G., Luisi B.F., Jones G.H. and Carpousis A.J., Running rings around RNA: a superfamily of phosphate-dependent RNases. Trends Biochem. Sci. 27: 11-18, 2002.

13. Coburn G.A. and Mackie G.A., Degradation of mRNA in Escherichia coli: an old problem with some new twists. Prog. Nuc. Acid Res. 62: 55-108, 1999.

14. Regnier P. and Arraiano C.M., Degradation of mRNA in bacteria: emergence of ubiquitous features. Bioessays 22: 235-244, 2000.

15. Leszczyniecka M., Kang D.C., Sarkar D., Su Z.Z., Holmes M., Valerie K. and Fisher P.B., Identification and cloning of human polynucleotide phosphorylase, hPNPase old-35, in the context of terminal differentiation and cellular senescence. Proc. Natl. Acad. Sci. USA 99: 16636-16641, 2002.

16. Sarkar D., Leszczyniecka M., Kang D.C., Lebedeva I.V., Valerie K., Dhar S., Pandita T.K. and Fisher P.B., Downregulation of Myc as a potential target for growth arrest induced by human polynucleotide phosphorylase (hPNPaseold-35) in human melanoma cells. J. Biol. Chem. 278: 24542-24551, 2003.

17. Sarkar D., Park E.S., Emdad L., Randolph A., Valerie K. and Fisher P.B., Defining the domains of human polynucleotide phosphorylase (hPNPaseOLD-35) mediating cellular senescence. Mol. Cell. Biol. 25: 7333-7343, 2005.

18. Chen H.W., Rainey R.N., Balatoni C.E., Dawson D.W., Troke J.J., Wasiak S., Hong J.S., McBride H.M., Koehler C.M., Teitell M.A. and French S.W., Mammalian polynucleotide phosphorylase is an intermembrane space RNase that maintains mitochondrial homeostasis. Mol. Cell. Biol. 26: 8475-8487, 2006.

19. Rainey R.N., Glavin J.D., Chen H.W., French S.W., Teitell M.A. and Koehler C.M., A new function in translocation for the mitochondrial i-AAA protease Ymel: import of polynucleotide phosphorylase into the intermembrane space. Mol. Cell Biol. 26: 8488-8497, 2006.

20. Cudny H. and Deutscher M.P., 3' Processing of tRNA precursors in ribonuclease-deficient Escherichia coli. Development and characterization of an in vitro processing system and evidence for a phosphate requirement. J. Biol. Chem. 263: 1518-1523, 1988.

21. Li Z. and Deutscher M.P., Maturation pathways for E. coli tRNA precursors: a random multienzyme process in vivo. Cell 86: 503-512, 1996.

22. Ishii R., Nureki O. and Yokoyama S., Crystal structure of the tRNA processing enzyme RNase $\mathrm{PH}$ from Aquifex aeolicus. J. Biol. Chem. 278: 32397-32404, 2003.

23. Choi J.M., Park E.Y., Kim J.H., Chang S.K. and Cho Y., Probing the functional importance of the hexameric ring structure of RNase PH. J. Biol. Chem. 279: 755-764, 2004.

24. Yehudai-Resheff S., Portnoy V., Yogev S., Adir N. and Schuster G., Domain analysis of the chloroplast polynucleotide phosphorylase reveals discrete functions in RNA degradation, polyadenylation, and sequence homology with exosome proteins. Plant Cell 15: 2003-2019, 2003.

25. Leszczyniecka M., DeSalle R., Kang D.C. and Fisher P.B., The origin of polynucleotide phosphorylase domains. Mol. Phylogenet. Evol. 31: 123-130, 2004.

26. Raijmakers R., Egberts W.V., van Venrooij W.J. and Pruijn G.J., Protein-protein interactions between human exosome components support the assembly of RNase PHtype subunits into a six-membered PNPase-like ring. J. Mol. Biol. 323: 653-663, 2002. 
27. Symmons M.F., Jones G.H. and Luisi B.F., A duplicated fold is the structural basis for polynucleotide phosphorylase catalytic activity, processivity, and regulation. Structure 8: 1215-1226, 2000.

28. Zuo Y. and Deutscher M.P., Exoribonuclease superfamilies: structural analysis and phylogenetic distribution. Nucleic Acids Res. 29: 1017-1026, 2001.

29. Lorentzen E., Walter P., Fribourg S., Evguenieva-Hackenberg E., Klug G. and Conti E., The archaeal exosome core is a hexameric ring structure with three catalytic subunits. Nat. Struct. Mol. Biol. 12: 575-585, 2005.

30. Buttner K., Wenig K. and Hopfner K.P., Structural framework for the mechanism of archaeal exosomes in RNA processing. Mol. Cell. 20: 461-471, 2005.

31. Liu Q., Greimann J.C. and Lima C.D., Reconstitution, activities, and structure of the eukaryotic RNA exosome. Cell 127: 1223-1237, 2006.

32. Jarrige A., Brechemier-Baey D., Mathy N., Duche O. and Portier C., Mutational analysis of polynucleotide phosphorylase from Escherichia coli. J. Mol. Biol. 321: 397-409, 2002.

33. Evguenieva-Hackenberg E., Walter P., Hochleitner E., Lottspeich F. and Klug G., An exosome-like complex in Sulfolobus solfataricus. EMBO Rep. 4: 889-893, 2003.

34. Lorentzen E. and Conti E., Structural basis of $3^{\prime}$ end RNA recognition and exoribonucleolytic cleavage by an exosome RNase PH core. Mol. Cell 20: 473-481, 2005.

35. Lorentzen E. and Conti E., The exosome and the proteasome: nano-compartments for degradation. Cell 125: 651654,2006

36. Portnoy V., Evguenieva-Hackenberg E., Klein F., Walter P., Lorentzen E., Klug G. and Schuster G., RNA polyadenylation in Archaea: not observed in Haloferax while the exosome polyadenylates RNA in Sulfolobus. EMBO Rep. 6: 1188-1193, 2005.

37. Buttner K., Wenig K. and Hopfner K.P., The exosome: a macromolecular cage for controlled RNA degradation. Mol. Microbiol. 61: 1372-1379, 2006.

38. Mitchel P., Petfalski E., Shevchenko A., Mann M. and Tollervey D., The exosome: a conserved eukaryotic RNA processing complex containing multiple $3^{\prime}$ to $5^{\prime}$ exoribonucleases. Cell 91: 457-466, 1997.

39. van Hoof A. and Parker R., The exosome: a proteasome for RNA?. Cell 99: 347-350, 1999.

40. Raijmakers R., Schilders G. and Pruijn G.J., The exosome, a molecular machine for controlled RNA degradation in both nucleus and cytoplasm. Eur. J. Cell Biol. 83: 175-183, 2004.

41. Houseley J., LaCava J. and Tollervey D., RNA-quality control by the exosome. Nat. Rev. Mol. Cell Biol. 7: 529539,2006

42. Chekanova J.A., Dutko J.A., Mian I.S. and Belostotsky D.A., Arabidopsis thaliana exosome subunit AtRrp4p is a hydrolytic $3^{\prime} \rightarrow 5^{\prime}$ exonuclease containing $\mathrm{S} 1$ and $\mathrm{KH}$ RNA-binding domains. Nucleic Acids Res. 30: 695-700, 2002.

43. Estevez A.M., Kempf T. and Clayton C., The exosome of Trypanosoma brucei. EMBO J. 20: 3831-3839, 2001.

44. Allmang C., Petfalski E., Podtelejnikov A., Mann M., Tollervey D. and Mitchell P., The yeast exosome and human PM-Scl are related complexes of $3^{\prime} \rightarrow 5^{\prime}$ exonucleases. Genes Dev. 13: 2148-2158, 1999.

45. Hernandez H., Dziembowski A., Taverner T., Seraphin B. and Robinson C.V., Subunit architecture of multimeric complexes isolated directly from cells. EMBO Rep. 7: 605610, 2006.

46. Burkard K.T. and Butler J.S., A nuclear $3^{\prime}-5^{\prime}$ exonuclease involved in mRNA degradation interacts with poly(A) polymerase and the hnRNA protein Npl3p. Mol. Cell Biol. 20: 604-616, 2000.

47. Deutscher M.P., Marshall G.T. and Cudny H., RNase PH: an Escherichia coli phosphate-dependent nuclease distinct from polynucleotide phosphorylase. Proc. Natl. Acad. Sci. USA 85: 4710-4714, 1988.

48. Mitchell P., Petfalski E., Houalla R., Podtelejnikov A., Mann M. and Tollervey D., Rrp47p is an exosomeassociated protein required for the $3^{\prime}$ processing of stable RNAs. Mol. Cell. Biol. 23: 6982-6992, 2003.

49. Dziembowski A., Lorentzen E., Conti E. and Seraphin B., A single subunit, Dis3, is essentially responsible for yeast exosome core activity. Nat. Struct. Mol. Biol. 14: 15-22, 2007.

50. Lin P.H. and Lin-Chao S., RhlB helicase rather than enolase is the beta-subunit of the Escherichia coli polynucleotide phosphorylase (PNPase)-exoribonucleolytic complex. Proc. Natl. Acad. Sci. USA 102: 16590-16595, 2005.

51. Py B., Higgins C.F., Krisch H.M. and Carpousis A.J., A DEAD-box RNA helicase in the Escherichia coli RNA degradosome. Nature 381: 169-172, 1996.

52. Anderson J.S. and Parker R.P., The $3^{\prime}$ to $5^{\prime}$ degradation of yeast mRNAs is a general mechanism for mRNA turnover that requires the SKI2 DEVH box protein and $3^{\prime}$ to $5^{\prime}$ exonucleases of the exosome complex. EMBO J. 17: 14971506, 1998.

53. Araki Y., Takahashi S., Kobayashi T., Kajiho H., Hoshino S. and Katada T., Ski7p G protein interacts with the exosome and the Ski complex for $3^{\prime}$-to-5' mRNA decay in yeast. EMBO J. 20: 4684-4693, 2001.

54. LaCava J., Houseley J., Saveanu C., Petfalski E., Thompson E., Jacquier A. and Tollervey D., RNA degradation by the exosome is promoted by a nuclear polyadenylation complex. Cell 121: 713-724, 2005.

55. Vasiljeva L. and Buratowski S., Nrdl interacts with the nuclear exosome for $3^{\prime}$ processing of RNA polymerase II transcripts. Mol. Cell 21: 239-248, 2006.

56. Tran H., Schilling M., Wirbelauer C., Hess D. and Nagamine Y., Facilitation of mRNA deadenylation and decay by the exosome-bound, DExH protein RHAU. Mol. Cell 13: 101-111, 2004.

57. Gherzi R., Lee K.Y., Briata P., Wegmuller D., Moroni C., Karin M. and Chen C.Y., A KH domain RNA binding protein, KSRP, promotes ARE-directed mRNA turnover by recruiting the degradation machinery. Mol. Cell 14: 571583, 2004.

58. Chen C.Y., Gherzi R., Ong S.E., Chan E.L., Raijmakers R., Pruijn G.J., Stoecklin G., Moroni C., Mann M. and Karin M., AU binding proteins recruit the exosome to degrade ARE-containing mRNAs. Cell 107: 451-464, 2001.

59. Kaberdin V.R., Miczak A., Jakobsen J.S., Lin-Chao S., McDowall K.J. and von Gabain A., The endoribonucleolytic N-terminal half of Escherichia coli RNase E is evolutionarily conserved in Synechocystis sp. and other bacteria but not the C-terminal half, which is sufficient for degradosome assembly. Proc. Natl. Acad. Sci. USA 95: 11637-11642, 1998.

60. Worrall J.A. and Luisi B.F., Information available at cut rates: structure and mechanism of ribonucleases. Curr. Opin. Struct. Biol. 17: 128-137, 2007. 
61. Marcaida M.J., DePristo M.A., Chandran V., Carpousis A.J. and Luisi B.F., The RNA degradosome: life in the fast lane of adaptive molecular evolution. Trends Biochem. Sci. 31: 359-365, 2006.

62. Portier C., van Rapenbusch R., Minh Nguy T. and Grunberg-Manago M., Quaternary structure of polynucleotide phosphorylase from Escherichia coli. Eur. J. Biochem. 40: 77-87, 1973.

63. Portier C., Quaternary structure of polynucleotide phosphorylase from Escherichia coli: evidence of a complex between two types of polypeptide chains. Eur. J. Biochem. 55: 573-582, 1975.

64. de la Cruz J., Kressler D., Tollervey D. and Linder P., Doblp (Mtr4p) is a putative ATP-dependent RNA helicase required for the $3^{\prime}$ end formation of $5.8 \mathrm{~S}$ rRNA in Saccharomyces cerevisiae. EMBO J. 17: 1128-1140, 1998.

65. Dziembowski A., Lorentzen E., Conti E. and Seraphin B., A single subunit, Dis3, is essentially responsible for yeast exosome core activity. Nat. Struct. Mol. Biol. 14: 15-22, 2007.

66. Yehudai-Resheff S., Hirsh M. and Schuster G., Polynucleotide phosphorylase functions as both an exonuclease and a poly(A) polymerase in spinach chloroplasts. Mol. Cell. Biol. 21: 5408-5416, 2001.

67. Slomovic S., Laufer D., Geiger D. and Schuster G., Polyadenylation of ribosomal RNA in human cells. Nucleic Acids Res. 34: 2966-2975, 2006.

68. Baginsky S., Shteiman-Kotler A., Liveanu V., YehudaiResheff S., Bellaoui M., Settlage R.E., Shabanowitz J., Hunt D.F., Schuster G. and Gruissem W., Chloroplast PNPase exists as a homo-multimer enzyme complex that is distinct from the Escherichia coli degradosome. RNA 7: 1464-1475, 2001. 